\title{
Comparison of Direct and Indirect Structural Analysis of HAZ after Laser Cutting in Amorphous Alloys
}

\author{
K. BÁN ${ }^{a, *}$, M. NAGY ${ }^{a}$, Zs. FogARASSY ${ }^{b}$ AND A. SZABÓ ${ }^{c}$ \\ ${ }^{a}$ Department of Automotive Technologies, Budapest University of Technology and Economics, \\ Stoczek street 6., 1111 Budapest, Hungary \\ ${ }^{b}$ Institute of Technical Physics and Materials Science, Hungarian Academy of Sciences, \\ Konkoly Thege Miklós út 29-33., 1121 Budapest, Hungary \\ ${ }^{c}$ Institute of Engineering, University of Dunaújváros, Táncsics M. street 1/a, 2401 Dunaújváros, Hungary \\ Heat affected zone (HAZ) of soft magnetic glassy alloys like METGLAS and FINEMET were examined after \\ $\mathrm{CO}_{2}$ laser cutting. Our investigations were focused on the structural changes of the HAZ of these soft mag- \\ netic materials examined by microhardness distribution as indirect, and as direct methods (SEM and TEM). \\ The comparison and validation of microhardness distribution with direct structural examinations were carried out. \\ This has a certain connection to mechanical properties like embrittlement and magnetic properties. The soft mag- \\ netic glassy alloys may become the base materials for the iron core of electric motors in order to boost their \\ efficiency. For this reason, it is essential to find the relevant cutting technology.
}

DOI: 10.12693/APhysPolA.137.861

PACS/topics: laser cutting, FINEMET, METGLAS, microhardness, heat affected zone, crystallization, amorphous, nanocrystalline

\section{Introduction}

For the enhanced efficiency (also increasing the energy saving tendency) it is inevitable to introduce modern soft magnetic materials in the electromotor production. These days, the stator and rotor in electric motors are made of conventional crystalline FeSi alloy plates mainly, which are produced by punching. The possibility of application of Fe-based glassy alloys requires consideration of the excellent magnetic properties and the very low losses in this respect. One the one hand, cutting by punching technology seems to be more complicated due to the great hardness of the soft magnetic materials, brittle behavior, and their low thickness $(20-30 \mu \mathrm{m})$. On the other hand, the punching press tool might be greatly frayed by the glass (and the crack initiation of the cut-off product is expected). Therefore, it is important to examine other cutting technologies like laser beam cutting.

On the contrary, the laser beam cutting has disadvantage due to the extension of the heat affected zone (HAZ), which can cause a remarkable structural change in the form of partial crystallization at nano and micro scale in amorphous materials. This can deteriorate the magnetic and mechanical properties of the manufactured rotor or stator segment.

According to $[1,2]$, one should expect to appear 5 various types of structural zones in the HAZ of amorphous soft magnetic materials. In FINEMET only structural

*corresponding author; e-mail: krisztian.ban@auto.bme.hu relaxation of glassy state may appear, moved from the base material (as-quenched state) to the cutting edge. During the steps of the crystallization process, in the 2nd zone $\mathrm{Cu}$-rich clusters appear. The both transition steps occur below $\sim 450^{\circ} \mathrm{C}$. In the zone 3 , the first crystalline phases are created $(\alpha-\mathrm{Fe}(\mathrm{Si})+$ amorphous FeNbB $)$ in the temperature range about $450-570^{\circ} \mathrm{C}$. Then, in the 4 th and 5 th zones (typically about $650-700^{\circ} \mathrm{C}$ and $700-750{ }^{\circ} \mathrm{C}$ ) the formation of boride crystalline phases occurs. For METGLAS the predicted zones are: 1 st is the structural relaxation, 2nd is the $\alpha$-Fe $(\mathrm{Si})$ + amorphous $\mathrm{FeB}\left(480-540^{\circ} \mathrm{C}\right)$, at 3 th and 4 th zones the $\alpha$-Fe $+\mathrm{Fe}_{3} \mathrm{~B}$ and the $\mathrm{Fe}_{2} \mathrm{~B}$ phases are formed, respectively. It is expected that the crystalline phases emerge in the burr but the mechanism of development is completely different because of the melt crystallization [1]

For the development of superior soft magnetic properties the definite stage of crystallization (partial) has to be achieved. If the crystallization process is not stopped at step 3 (in case of FINEMET), the average grain size of the resulted $\alpha-\mathrm{Fe}(\mathrm{Si})$ solid solution will be larger than the desired one, i.e., from 10 to $15 \mathrm{~nm}$ (being formed via primary crystallization) [3]. In addition, also Fe-boride phases are formed from the residual amorphous part of the ribbon. From the crystallization of the melted burr, the crystal and boride phases are expected in micrometer range. Consequently, the crystalline Fe borides increase the coercive force, and their appearance increase the magnetic loss [2]. If this process occurs in the laser cut zone, it expands the magnetic hysteresis loop of the glassy alloy in this environment. Due to the laser cutting, the higher temperature increases the hardness of the material (which had a high initial hardness also), and then it becomes easily breakable [1]. 
As part of the studies, amorphous soft magnetic materials based on direct and indirect structural analysis were examined. The subject of this examination was to identify the phases appeared in the HAZ and to determine their ranges.

Another parallel examination [1] was to compare the X-ray diffraction with micro-hardness measurements, respectively, as a direct and an indirect structural analysis made after laser cutting on FINEMET and METGLAS specimens. The XRD difficulty was that it provided a summary information about the structure of the cut zone (as-quenched, HAZ and burr also). It was therefore impossible to separate which structural characteristic belonged to which zone of the HAZ. For this purpose, local structural examinations as Scanning Electron Microscopy (SEM) and Transmission Electron Microscopy (TEM) were carried out.

\section{Experiments}

In this study, the local structural change in $\mathrm{FeSiBNbCu}$ (FINEMET) with an average thickness of $20 \mu \mathrm{m}$, and $\mathrm{FeSiB}$ (METGLAS) with $25 \mu \mathrm{m}$ were investigated after laser beam cutting. Ribbons were cut by a $\mathrm{CO}_{2}$ type laser (OPL 2000 equipment, manufactured by Oerlicon). During the cutting process, argon protective gas was applied to perform the cutouts. The laser beam power was $60 \mathrm{~W}$ in a continuous mode, and a laser beam feed rate was $1200 \mathrm{~mm} / \mathrm{min}$. The ribbons were tightly fixed with a strong adhesive tape, from which $20-25 \mathrm{~mm}$ long and $10 \mathrm{~mm}$ wide parallel strips were cut out.

The first examination was the microhardness distribution measurements on the cut edge. Both materials were measured by CSM Micro Combi Tester for integrated microhardness meter and microscope analyzer. With a Vickers tip 80 pound load $(784.8 \mathrm{mN}$ with a $15 \mathrm{~s}$ holding time) was applied during the measurements. The further examinations were the Scanning Electron Microscope (SEM) and Transmission Electron Microscope (TEM) measurements. For the TEM investigations a Philips CM-20 operated at $200 \mathrm{kV}$ accelerating voltage equipped with a Bruker X-ray detector (EDS) were used. The TEM samples were prepared by ion beam milling. The ProcesDiffraction [4-6] program was also used to evaluate the SAED diffractions, and to present their results.

\section{Results and discussion}

A microhardness distribution of FINEMET and METGLAS specimens (see Fig. 1) was prepared at a load of 80 pound after cut with $\mathrm{CO}_{2}$ laser.

The first imprint was measured $50 \mu \mathrm{m}$ from the cut edge. At $100 \mu \mathrm{m}$ the highest value of about 1600 HV0.08 was obtained. Next, the values started to decrease continually until they reached the initial hardness. The HAZ of METGLAS was $\approx 200-250 \mu \mathrm{m}$ [1]. We have to remark that there is an uncertainty in determination of HAZ

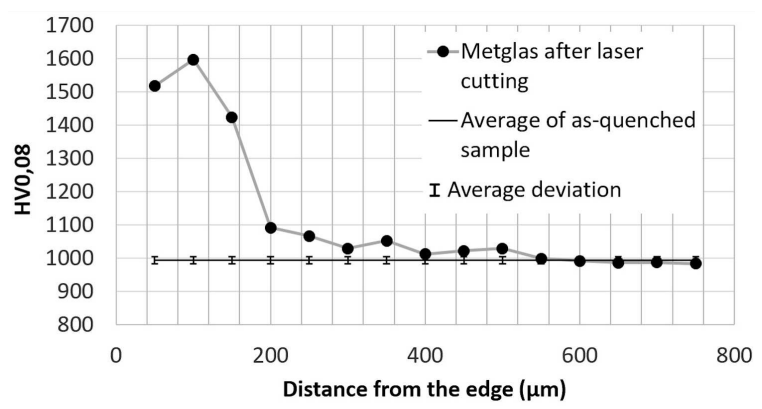

Fig. 1. The microhardness values of METGLAS after laser cutting versus the distance from the cut edge.

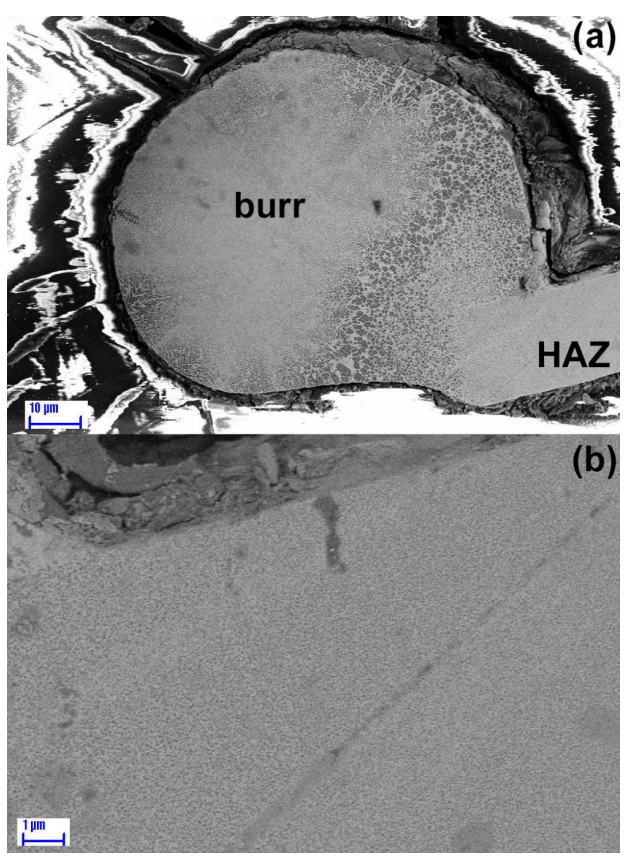

Fig. 2. SEM pictures of the shape of melting burr (a), and (b) crystallites near to the melting burr of the FINEMET sample.

on the basis of microhardness measurements because of the burr. Note that before the microhardness measurement the burr should be grinded down. This meant that from the edge we removed $40-80 \mu \mathrm{m}$ (the diameter of the burr was $60-100 \mu \mathrm{m}$ ) which depended on the position of the burr (Fig. 2). The results of microhardness distribution at FINEMET can be found in [1]. The highest value was $1492 \mathrm{HV} 0.08$, and around $150-200 \mu \mathrm{m}$ from the edge it reached the basic hardness (1000 HV0.08).

On the SEM picture (Fig. 2) the structure of the burr (crystallization from the melt), and the HAZ were well separated. The crystalline phases around $1 \mu \mathrm{m}$ range could be seen in the burr.

In the HAZ of the raw material the size of the crystallites were reduced to $\mathrm{nm}$ scale (see Fig. 2b). At first, the size of the crystallites was examined by SEM at $26 \mu \mathrm{m}, 82 \mu \mathrm{m}, 106 \mu \mathrm{m}$, and finally at $130 \mu \mathrm{m}$, from 
the neck of the burr. As the crystallites were barely visible at a $106 \mu \mathrm{m}$ distance from the melting burr, then at $130 \mu \mathrm{m}$ they were no more detectable. This HAZ was estimated by the microhardness measurements on FINEMET (150-200 $\mu \mathrm{m})$, taking into account the size and the position of the burr.

In the case of TEM at a sample of FINEMET, moving inwardly from the neck of the burr into the ribbon, the size of the crystallites gradually decreased. At a distance of $10 \mu \mathrm{m}$ from the burr, the average size of the larger crystallites were $80 \mathrm{~nm}$ (see Fig. 3a), while in the case of $100 \mu \mathrm{m}$, only $20 \mathrm{~nm}$. At a distance of $10 \mu \mathrm{m}$ small crystals of a few $\mathrm{nm}$ could be observed in larger crystallites and their grain boundaries. This dual structure resulted in a parallel concentric line system, as one can see in the deflection image (Fig. 3b). Among more intense broken lines, less intense but continuous lines were visible as well. More intense signs were derived from the larger average size bcc-Fe( $\mathrm{Si}$ ) phase, while continuous lines could be identified by the $\mathrm{Fe}_{3} \mathrm{~B}$ phase (see Fig. 3c). At a distance of $150-200 \mu \mathrm{m}$ from the neck of the burr, the structure of the ribbon was already amorphous according to the SEM measurements. TEM studies, however, showed that there were still a few $\mathrm{nm} \mathrm{Fe}(\mathrm{Si})$ crystallites in the amorphous matrix. With such a weak intensity, no distinction could be made between bcc-Fe and $\mathrm{Fe}_{3} \mathrm{Si}$ crystallites. The both phases are distinguishable only by the scale to which $\mathrm{Si}$ is arranged within the bcc crystal structure. In fact, it results twice higher lattice parameter.

The sample crystallized completely close to the burr in the METGLAS sample. Dual phase structure in dimension was also detected. Crystallites with larger size of 100-150 nm were found, however, crystallites of $10 \mathrm{~nm}$ range were more visible. The presence of the dual structure was reflected in the diffraction rings. The analysis of the electron diffraction intensity revealed that the $\mathrm{Fe}_{3}(\mathrm{~B}, \mathrm{Si})$ crystallites were larger, while the smaller crystallites were in $\mathrm{Fe}_{2} \mathrm{~B}$ phases.

Moving $50 \mu \mathrm{m}$ inward to the HAZ from the neck of the burr, the sample was still crystalline but the crystallite size was already one order of magnitude smaller (around $10 \mathrm{~nm}$ ). At a distance of $150 \mu \mathrm{m}$ the size was only $2-3 \mathrm{~nm}$ (with the amorphous maximum a faint line in the diffraction pattern was visible).

\section{Conclusions}

In the close vicinity of laser cutting $\left(\mathrm{CO}_{2}\right.$ laser in continuous mode, $60 \mathrm{~W}$ ), melt formation and structural changes in the HAZ were observed at METGLAS and FINEMET samples. According to the indirect structural examination (microhardness measurement) we found good correspondence with the results of direct methods (SEM and TEM). The impact zone of heat effect was 150-200 $\mu \mathrm{m}$ for FINEMET, and slightly higher for METGLAS 200-250 $\mu \mathrm{m}$. The difference within the uncertainty of HAZ determination with microhardness measurements

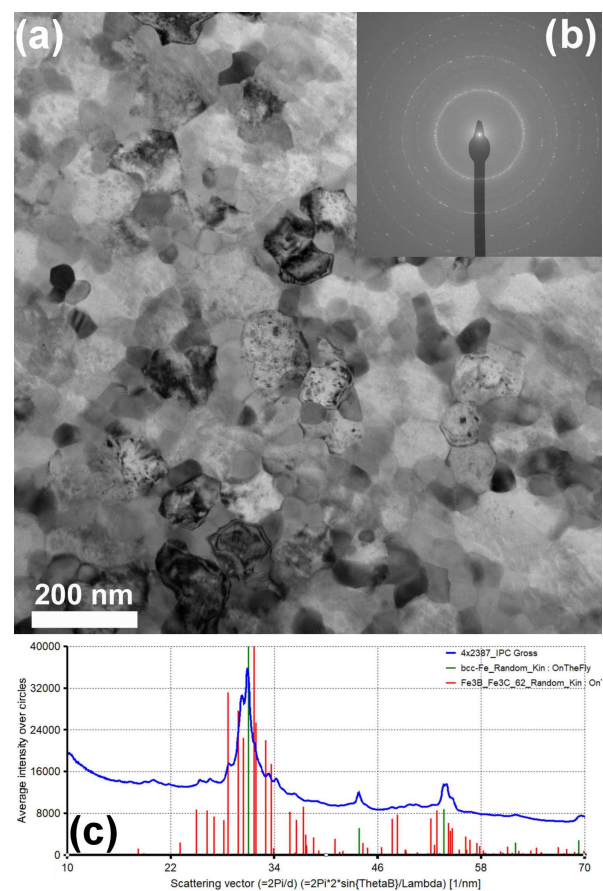

Fig. 3. Bright-field (BF) TEM image (a), and (b) selected area electron diffraction (SAED) pattern at a distance of $10 \mu \mathrm{m}$ from the neck of the burr for FINEMET sample. (c) The distribution of the electron diffraction intensity calculated from the SAED pattern.

is related to the size and the position of the burr. The predicted phases were identified in the HAZ by direct structural examination.

\section{Acknowledgments}

The research presented in this paper was carried out as a part of the EFOP-3.6.2-16-2017-00016 project in the framework of the New Széchenyi Plan. The completion of this project is funded by the European Union and co-financed by the European Social Fund. Authors thank to Noémi Szász for TEM sample preparation and Levente Illés for the help in the SEM measurements.

\section{References}

[1] K. Bán, M. Nagy, Á. Cziráki, Zs. Fogarassy, in: Advanced Manufacturing and Repair Technologies in Vehicle Industry: 35th International Colloquium, Zielona Góra (Poland) 2018, monograph, p. 17.

[2] Z. Weltsch, K. Klam, A. Lovas, Acta Phys. Pol. A 131, 669 (2017).

[3] G. Herzer, in: Handbook of Magnetic Materials, Ed. K.H.J. Buschow, Vol. 10, Ch. 3, Elsevier Sci., Amsterdam 1997, p. 415.

[4] J.L. Lábár, Microsc. Microanal., 14, 287 (2008).

[5] J.L. Lábár, Microsc. Microanal. 15, 20 (2009).

[6] M. Adamik, B.P. Barna, Zs. Czigány et al., Microsc. Microanal. 18, 406 (2012). 